\title{
Metody badań złączy spawanych na superstopie Inconel 713C - nieniszczące badania penetracyjne oraz obserwacje mikroskopowe
}

\author{
Methods of testing of welded joints \\ made of Inconel 713C superalloy - penetrant testing \\ and microscopic observations
}

\section{Streszczenie}

W pracy przedstawiono wyniki badań przeprowadzonych w celu oceny przydatności nieniszczących badań penetracyjnych w zastosowaniu do badania złączy spawanych wykonanych na superstopie niklu Inconel 713C. Jako metodę odniesienia wykorzystano obserwacje mikroskopowe. Stwierdzono, że metoda penetracyjna nie ujawniła wszystkich pęknięć wykrytych podczas obserwacji mikroskopowych.

Słowa kluczowe: Inconel 713C; połączenia spawane; superstopy niklu; badania penetracyjne

\begin{abstract}
The paper presents results of the research performed in order to examine the efficiency of using of penetrant testing method to detect welding defects in welding joints made of Inconel 713C alloy. As a reference method, the microscopic observations have been used. It has been found that the penetrant testing method does not reveal all the cracks which can be detected using microscopic observations.
\end{abstract}

Keywords: Inconel 713C; welding joints; nickel superalloys; penetrant testing

\section{Wprowadzenie}

Należący do grupy nadstopów niklu Inconel 713C jest superstopem odlewniczym na osnowie austenitu $y$ umocnionego fazą międzymetaliczną $\mathrm{Ni}_{3} \mathrm{AlTi}-\mathrm{\gamma}^{\prime}$. Jest on uważany za stop trudnospawalny, co wynika z jego dużej skłonności do pękania podczas spawania oraz w czasie powtórnego nagrzewania do temperatury pracy lub obróbki cieplnej. Pęknięcia powstające w spoinach są zwykle pęknięciami krystalizacyjnymi. Bardziej niebezpieczne są jednak pęknięcia powstające w strefie wpływu ciepła (SWC), które trudno jest wyeliminować głównie ze względu na nie do końca poznany mechanizm powstawania [1].

Stop Inconel 713C charakteryzuje doskonała odporność na korozję wysokotemperaturową oraz odporność na pełzanie. Należy zaznaczyć, iż nadstopy niklu nie są materiałami projektowanym z zamiarem łączenia ich za pomocą technik spawalniczych. Mimo to, ze względu na szczególne zastosowania tych stopów i konieczność np. napawania komór spalania w silnikach okrętowych czy spawania łopatek do piast silników turbospalinowych, na świecie prowadzonych jest wiele badań poświęconych spawaniu i napawaniu tych stopów [2,3]. Dlatego istotne jest poznanie możliwości metod badawczych, służących ocenie jakości złączy spawanych wykonanych na nadstopach niklu, zwłaszcza metod nieniszczących, umożliwiających przeprowadzenie badań bez konieczności niszczenia obiektu badanego.

Jedną z metod badań nieniszczących są badania penetracyjne (PT). Jest to metoda wykrywania pęknięć powierzchniowych. Polega na pokryciu oczyszczonej powierzchni środkiem penetrującym i usunięciu jego nadmiaru po upływie odpowiedniego czasu, naniesieniu wywoływacza i odczycie ujawnionych wskazań. Uważa się, że badania penetracyjne umożliwiają identyfikację wad powierzchniowych wszystkich materiałów nieporowatych.

Mgr inż. Dominika Nowak, dr inż. Maciej Lachowicz, prof. dr hab. inż. Andrzej Ambroziak - Politechnika Wrocławska.

Autor korespondencyjny/Corresponding author: dominikazofianowak@gmail.com 


\section{Materiał i metodyka badań}

W badaniach zastosowano stop Inconel o składzie chemicznym: 12,8 \%Cr, 4,15 \%Mo, 1,73\%Nb, 6,2 \%Al, 1,04 \%Ti, $0,12 \% \mathrm{C}, 0,017 \%$ B, 5 ppm Zr, 0,19\%Fe, Ni - reszta. Złącza spawane wykonano na płytkach o wielkości $35 \times 30 \times 5 \mathrm{~mm}$, które ukosowano na $V$ pod kątem ok. $30^{\circ}$ (ukosowanie złącza wynosiło ok. $60^{\circ}$ ). Po wykonaniu złącza uzyskiwano płytkę o długości ok. $72 \mathrm{~mm}$. Spawano metodą GTA, prądem przemiennym o natężeniu o wartości $70 \div 80$ A i napięciu średnim ok. $25 \mathrm{~V}$. Za stopiwo służyły pręciki o średnicy ok. 2,5 mm ze stopu In713C. Spawano ręcznie w pozycji podolnej, spoiną czołową w jednym przejściu. Prędkość spawania wynosiła $0,12 \mathrm{~m} / \mathrm{min}(2 \mathrm{~mm} / \mathrm{s})$. Zastosowano 5 poziomów temperatury podgrzania przed spawaniem: $300{ }^{\circ} \mathrm{C}, 400{ }^{\circ} \mathrm{C}, 500{ }^{\circ} \mathrm{C}, 600{ }^{\circ} \mathrm{C}$ i $700{ }^{\circ} \mathrm{C}$.

Po spawaniu wykonane spoiny poddano ocenie wizualnej. Następnie przeprowadzono badania penetracyjne zgodnie z normą PN-EN ISO 3452-1 przy użyciu penetranta barwnego. Badania prowadzono bezpośrednio na odtłuszczonych licach spoin. Zastosowano zmywacz MR79, penetrant MR68 i wywoływacz MR70. Czas wnikania penetranta oraz wywoływania wynosił 20 min dla każdego z etapów. Badanie przeprowadzono przy oświetleniu 800 lux.

W celu oceny skuteczności przeprowadzonych badań penetracyjnych, analizowane złącza poddano także obserwacjom mikroskopowym przy użyciu mikroskopu stereoskopowego, skaningowego mikroskopu elektronowego JEOL 5800 oraz mikroskopu konfokalnego Nikon LV150.

\section{Omówienie wyników badań}

$\mathrm{Na}$ podstawie oceny wizualnej wykonanych złączy we wszystkich spoinach stwierdzono występowanie pęknięć w spoinie lub w SWC. Przykładowo, w próbce podgrzanej do $500{ }^{\circ} \mathrm{C}$ (P500) stwierdzono 7 pęknięć, w tym dwa w prawej SWC oraz cztery w lewej SWC. Długość pęknięć wynosiła od 0,5 do 1,5 mm. Na końcu spoiny w kraterze występowało pęknięcie wzdłużne o długości ok. $1 \mathrm{~mm}$. Makroskopowy obraz spoiny P500 pokazano na rysunku 1, na którym liniami wskazano miejsca występowania pęknięć. Linie te odsunięto od SWC, aby nie zaciemnieć obrazu spoiny. Obraz stereoskopowy przykładowego pęknięcia obserwowanego w SWC przedstawiono na rysunku 2.

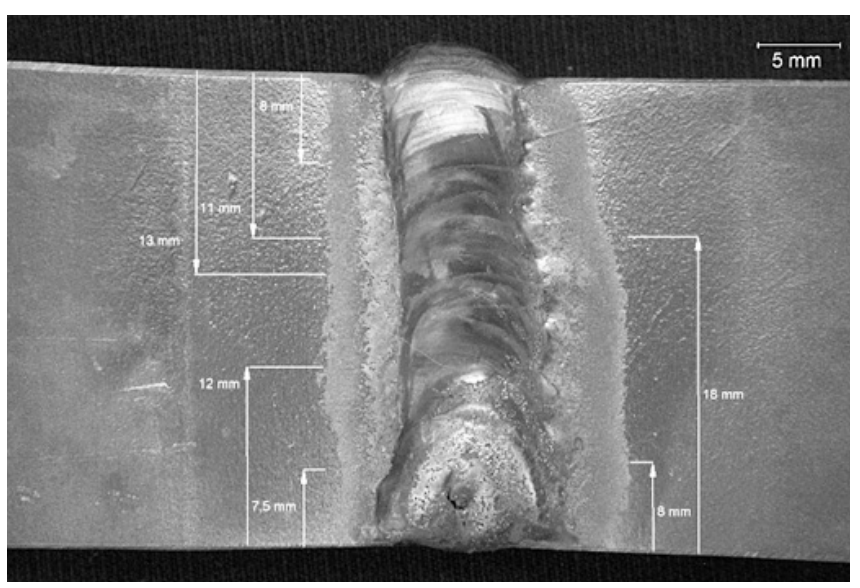

Rys. 1. Makroskopowy obraz spoiny P500 z naniesionymi liniami wskazującymi miejsce występowania pęknięć

Fig. 1. Macroscopic image of a P500 weld with lines showing the location of cracks

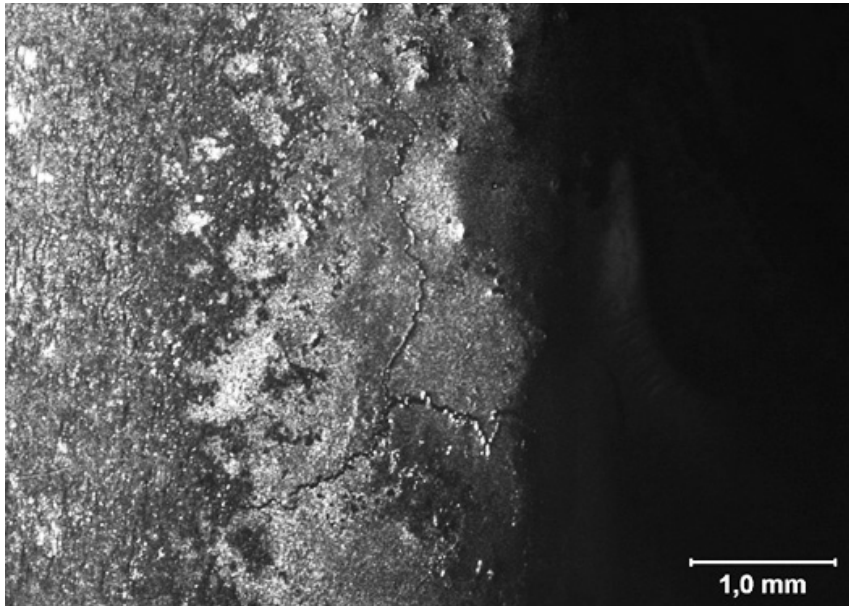

Rys. 2. Obraz stereoskopowy pęknięcia obserwowanego w SWC próbki podgrzanej do $500{ }^{\circ} \mathrm{C}$ (P500)

Fig. 2. Stereoscopic image of cracks observed in the HAZ of sample heated to $500{ }^{\circ} \mathrm{C}$

Przeprowadzone na wykonanych próbkach badania penetracyjne nie ujawniły wszystkich pęknięć zaobserwowanych podczas oceny wizualnej. Barwne wskazania pojawiły się w miejscach występowania nieciągłości na powierzchni lica spoiny (rys. 3). Natomiast większość pęknięć wykrytych w SWC podczas badań makroskopowych nie została ujawniona. Wynika to z faktu, że pęknięcia w SWC są niewielkie i mają długość do 1,5 mm oraz niewielkie rozwarcie, gdyż stanowią one jedynie nieciągłość na granicy ziarna.

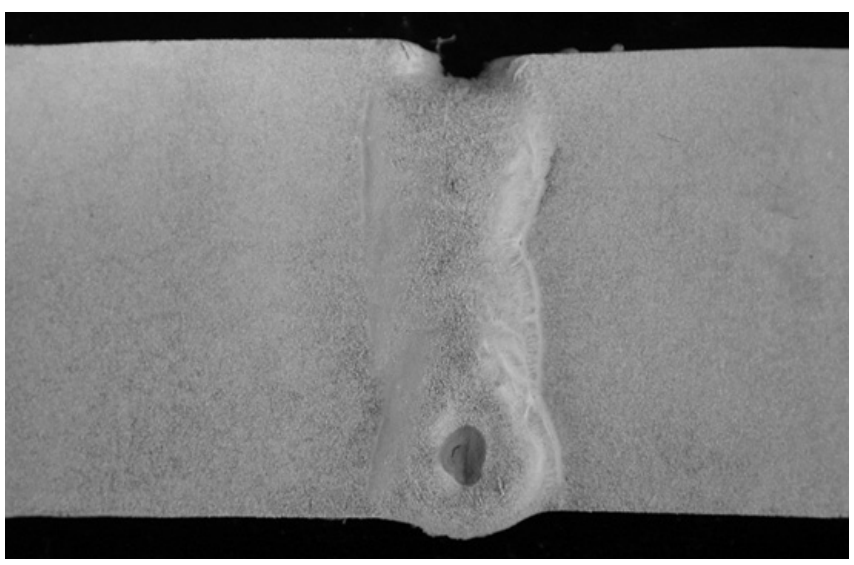

Rys. 3. Spoina P500 poddana badaniom penetracyjnym po upływie czasu wywoływania

Fig. 3. Welding joint P500 subjected to penetration tests after the development time

Zaobserwowane podczas obserwacji makroskopowych pęknięcia występujące w SWC, które nie zostały wykryte przy pomocy badań penetracyjnych, poddano analizie przy użyciu mikroskopu skaningowego oraz konfokalnego. Obraz mikroskopowy pęknięcia przedstawiono na rysunkach 4 i 5.

Wykonano także profil powierzchni wzdłuż linii przecinającej najgłębsze miejsce obserwowanego pęknięcia (rys. 6). Profil przedstawiony na rysunku 7 umożliwia ocenę geometrii pęknięcia, którego głębokość przy powierzchni wynosi $5,3 \mu \mathrm{m}$, rozwarcie natomiast osiąga szerokość ok. $30 \mu \mathrm{m}$. Rzeczywista głębokość pęknięcia była większa od zmierzonej, co potwierdziły badania przeprowadzone po szlifowaniu powierzchni lica. Pomimo zastosowania mikroskopii konfokalnej, odwzorowanie budowy pęknięcia bez wykonania zgładu metalograficznego nie było możliwe. Wynika to z morfologii pęknięcia, które jest tworzone przez ciągłą mikroporowatość na styku dendrytów krystalizacji, co pokazano na rysunku 4. 


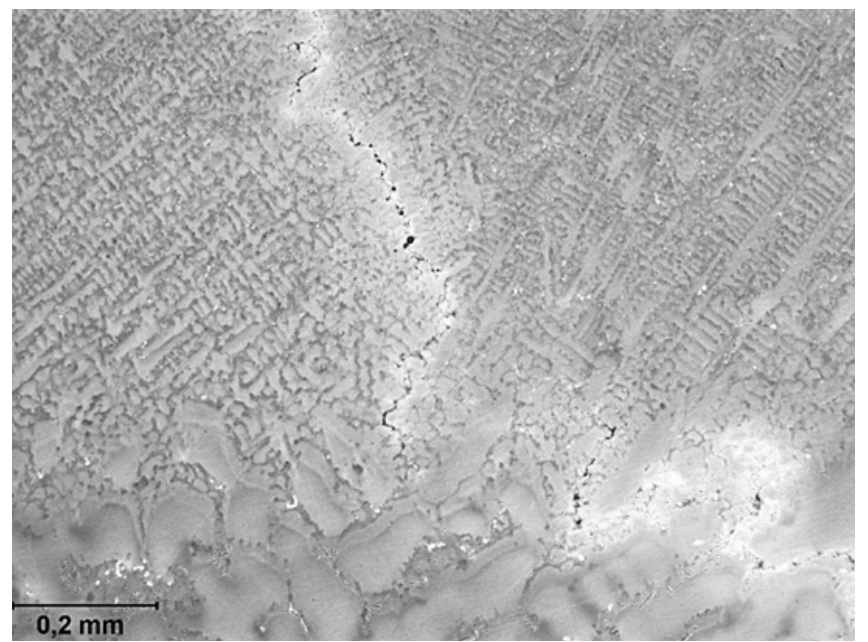

Rys. 4. Obraz mikroskopowy przekroju pęknięcia obserwowanego w SWC próbki P500, przedstawionego na rysunku 2. SEM

Fig. 4. Microscopic image of cross-section of the crack observed in the HAZ of P500 sample, shown in Figure 2. SEM

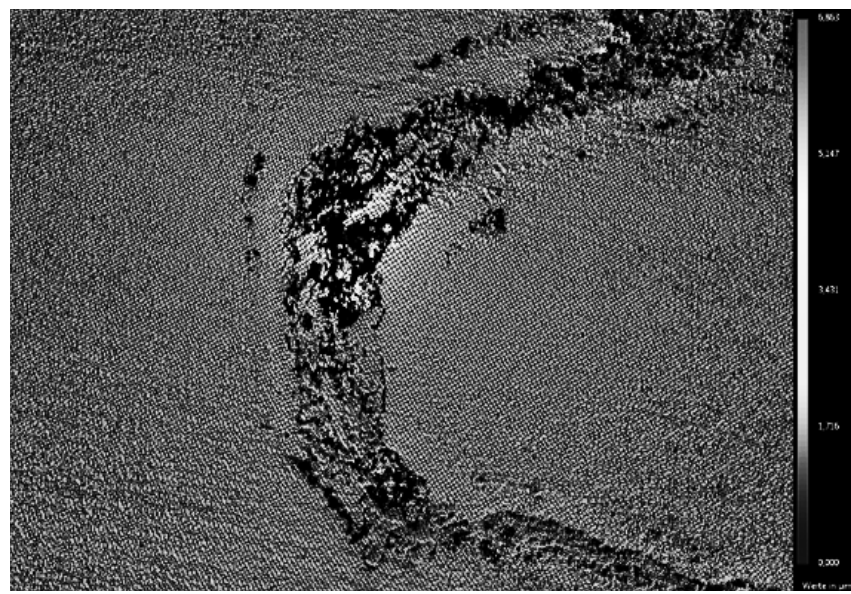

Rys. 5. Obraz mikroskopowy pęknięcia obserwowanego w SWC próbki P500, przedstawionego na rysunku 2

Fig. 5. Microscopic image of the crack observed in the HAZ of P500 sample, shown in Figure 2

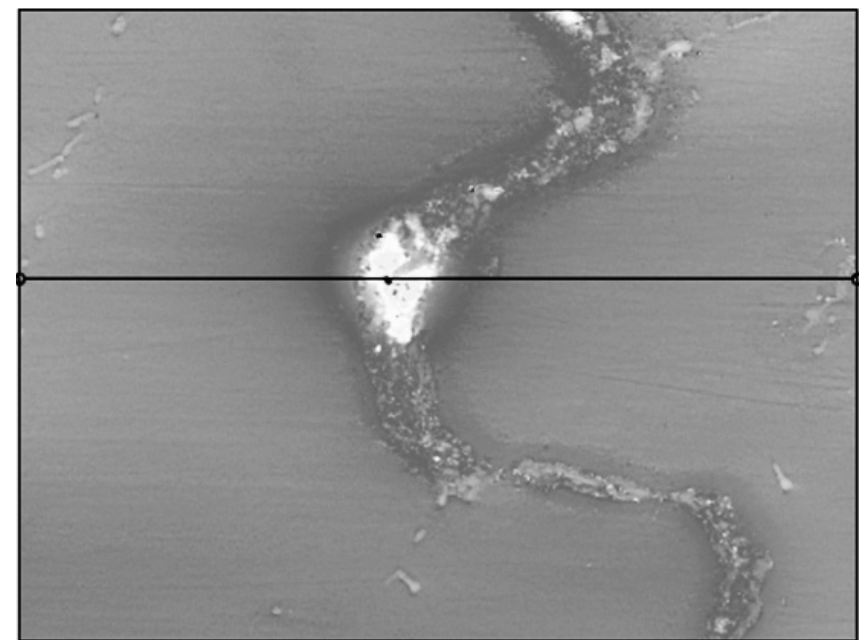

Rys. 6. Obraz mikroskopowy pęknięcia obserwowanego w SWC próbki P500, przedstawionego na rysunku 2 z naniesioną linią wykonania profilu powierzchni

Fig. 6. Microscopic image of the crack observed in the HAZ of P500 sample, shown in Figure 2, with the line of surface profile

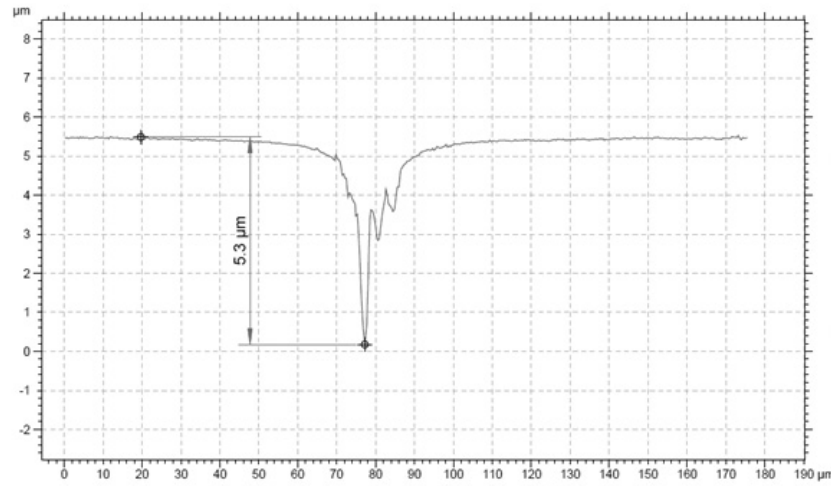

Rys. 7. Profil powierzchni utworzony wzdłuż linii przecięcia pęknięcia przedstawionej na rysunku 6

Fig. 7. Surface profile formed along the crack intersection shown in Figure 6

\section{Wnioski}

Na podstawie przeprowadzonych badań stwierdzono, że nieniszczące badania penetracyjne nie ujawniły wszystkich wad powstałych podczas spawania superstopu Inconel 713C, możliwych do wykrycia przy pomocy obserwacji makro i mikroskopowych. W trakcie badań stwierdzono, że spawany materiał Inconel 713C wykazuje małą zwilżalność przez penetrant, co jest szczególnie ważną oraz zaskakującą obserwacją. Pomimo że penetranty są cieczami o bardzo małym napięciu powierzchniowym, zwilżalność powierzchni płytek i spoin jest niewielka.

Na podstawie przeprowadzonych obserwacji można stwierdzić, że badania penetracyjne w zastosowaniu do badanego stopu muszą być poprzedzone większą ilością prób oraz zdobyciem większego doświadczenia. Dodatkowo badania muszą być potwierdzane obserwacjami mikroskopowymi, ponieważ pęknięcia o wielkości poniżej 1,5 mm mogą nie być wykrywane. Mając na uwadze, że badania penetracyjne przeprowadzono na małych, dokładnie przygotowanych próbkach, zastosowanie ich w warunkach przemysłowych może się wiązać z błędną interpretacją wyników. Należy również przeprowadzić próby na innych gatunkach nadstopów niklu.

\section{Literatura}

[1] M. Lachowicz: Charakterystyka napoin oraz pęknięć powstałych podczas napawania superstopu Inconel 713C, Inżynieria Materiałowa, nr 3/2006, rok XXVII

[2] O. A. Ojo, N. L. Richards, M.C. Chaturvedi: Contribution of constitutional liquation of gamma prime precipitate to weld HAZ cracking of cast Inconel 738 superalloy, Scripta Mat. 50, 2004
[3] M. B. Henderson, D. Arrell, M. Heobel, R. Larsson, G. Marchant: Nickel-Based Superalloy Welding Practices for Industrial Gas Turbine Applications, www.msm.com.ac.uk/phase-trans/2002 /papers/APNickelWeldv2.pdf 